\title{
Hydraulic Jump in Circular Open Channels with Mild Slope
}

\author{
Mona H. Rashed ${ }^{1}$, Tamer A. Gado ${ }^{2}$, and I. M. H. Rashwan ${ }^{3}$ \\ 1 Civil Engineering, Egypt, (monarashed504@yahoo.com) \\ ${ }^{2}$ Assistant Professor, is with Irrigation and Hydraulic Engineering Department, Faculty of Engineering, Tanta University, \\ Tanta, Egypt, (e-mail: tamer.gado@f-eng.tanta.edu.eg; tamergado@ hotmail.com) \\ ${ }^{3}$ Hydraulic Professor, is with Irrigation and Hydraulic Engineering Department, Faculty of Engineering, Tanta University, \\ Tanta, Egypt, (e-mail: ibrahim.rashwan@f-eng.tanta.edu.eg,imh_rashwan@yahoo.com)
}

\begin{abstract}
A hydraulic jump is a well-known transitional phenomenon from supercritical to subcritical flows with undulations of water-surface. In this transition, the water flow has a high-velocity, water surface rises abruptly, surface rollers are formed, intense mixing occurs, the air is entrained, and a large amount of energy is dissipated. In the present study characteristics of the hydraulic jumps in circular open channels with a mild sloped have been discussed under a wide range of experimental conditions. The study aims to determine the effect of the channel's mild slope on the characteristics of the hydraulic jumps with circular channels. A theoretical study has been done and led to obtaining equations that can be used to get specific force for the hydraulic jump that occurred in circular open channels. A theoretical study is based on using momentum, and Froude's number equations. An experimental study has been investigated using Laboratory 40 experimental runs in circular section flume for eight different discharges ranged from 3.92 to $12.07 \mathrm{l} / \mathrm{sec}$ were given with mild slope equals 0.000833 . In total, the experiments were conducted over a range of Froude numbers from 1.78 to 8.87 . The experimental works concluded some dimensionless curves and new useful formulas to get the length of the jump, energy dissipated and efficiency. The conjugated depth ratio is determined and plotted versus the upstream Froude number, downstream Froude number, head loss, and efficiency for different values of critical depths. The resulting graphs and equations of the present study are readily applicable for a design for the hydraulic jumps in the circular open channels with mild slope.
\end{abstract}

Keywords: Hydraulic Jump, Mild Slope, Specific Force, Conjugated depth, Froude Number, Energy Dissipated.

\section{INTRODUCTION}

$\mathrm{H}$ YDRAULIC jumps have been excessively used for energy dissipation downstream of hydraulic structures. The hydraulic jump may occur when there is supercritical flow in a channel having an obstruction or a rapid change in the cross-sectional area. When jump happens the flow changes from supercritical flow to subcritical flow. The analysis of this hydraulic phenomenon has been studied by many researchers during the last century, but there are still many aspects that should be studied. In first the hydraulic jump was investigated experimentally by Bidone, an Italian, in 1818, to determine the location of the jump. Thereafter, many studies were made and the results were quoted by many engineers. Chow (1959) explored the hydraulic jump and gave types of hydraulic jump on the horizontal floor according to the upstream
Froude number for rectangular cross-section open channels. Then most of the studies carried out on the hydraulic jump include the formation of the hydraulic jump in rectangular within sloped channels by (Rajaratnam and Murahari 1974; Hager 1989; Demetriou and Dimitriou 2008; and Eyo 2011). In contrast, different studies have been conducted on the hydraulic jump in non-rectangular channels. Hager and Wanoschek (1987) analytically studied of the hydraulic jump characteristics in triangular channels. They investigated the sequent depth ratio, the roller length and the jump length for different Froude numbers. Stahl and Hager (1999) by conducting an experimental study determined the sequent depth ratio in terms of the approach Froude number based on the conventional momentum approach for various Froude numbers from 1.5 to 6.5. Ead and Ghamry (2002); performed the results of a laboratory study of hydraulic jumps in circular conduits. They made experiments for a range of upstream Froude numbers $F_{r 1}$ from 1.29 to 6.43 and a range of the flow rate $Q$ from 7 to $35 \mathrm{l} / \mathrm{s}$ in a circular pipe $0.3 \mathrm{~m}$ in diameter. Rashwan, (2004); explained the hydraulic jump in circular open channels. In his paper, the momentum principle was applied to give an equation expressed in the hydraulic jump. Bushra and Afzal (2006) by analyzing the Reynolds equations of mean turbulent flow in a two-dimensional open channel of arbitrary cross-section estimated the turbulent structure of hydraulic jumps in circular and U-shaped channels for predicting the sequent depth ratio of hydraulic jumps. Mitchell (2008) demonstrated the hydraulic jumps in trapezoidal and circular channels. He offered a series of algorithms for calculating the ratio of conjugate depths in a hydraulic jump in a horizontal channel over a range of Froude numbers and for a range of various trapezoidal and circular sections. Vatankhah and Omid (2010) introduced an analytical method for studying the hydraulic jump in triangular channels. Their solution predicts the sequent depth ratio using the specific force equation. The study of the hydraulic jump in circular channels has been also given by some researchers. Khan (2013); performed an analytical analysis of hydraulic jump in the triangular channel. Rashwan (2013); studied A-jump in a horizontal inverted semicircular open channel. Reham (2015); studied the hydraulic jump in horizontal circular open channel theoretically and experimentally. A theoretical study gave good form to calculate the specific force and the specific 
energy for the hydraulic jump in a circular open channel in exact forms and two approximate forms. The applying of the developed equations on the experimental results a percentage error has been giving ranging from $3.2 \%$ to $9 \%$. Also, the experimental works gave an equation to estimate the hydraulic jump length by knowing the initial depth or the height of the jump and the specific force. Azimi et al. (2017); demonstrated the 3D pattern of hydraulic jumps in U-shaped open channels numerically the Flow-3D software. Wang and Samuel (2018); Studied the hydraulic jump and resultant flow choking in a circular sewer pipe of a steep slope. This research has given good curves of the maximum filling ratio and discharge capacity for free-surface flow downstream of the hydraulic jump. These curves delineate the region where the downstream flows would become a pressurized flow, which should be avoided in the design of storm sewers.

The present study aims to investigate the flow characteristics of the hydraulic jumps occurred in circular open channels with mild slope.

\section{Methodology}

Hydraulic jump in sloping circular open channels with a mild slope can be described as shown in Figure (1).

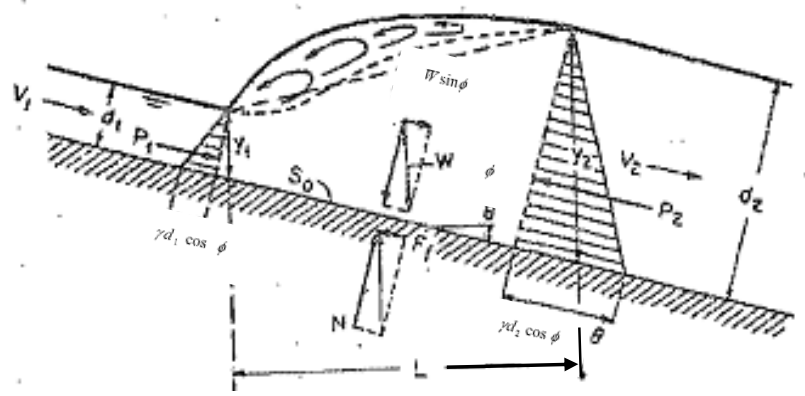

Figure (1) Longitudinal Section of the Hydraulic Jump in Sloping CircularOpen Channel, after Chow (1959)

It may be governed by the momentum equation as follows: $\rho Q\left(\beta_{2} V_{2}-\beta_{1} V_{1}\right)=\mathrm{P}_{1}-\mathrm{P}_{2}+W \sin \phi-F_{f}$

Where, $\rho=$ water density, $Q=$ discharge, $\beta_{1}=$ momentum coefficient in section $1, \beta_{2}=$ momentum coefficient in section $2, V_{1}=$ mean flow velocity at section $1, V_{2}=$ mean flow velocity at section $2, \mathbf{P}_{1}=$ hydrostatic pressure at section $1, \mathrm{P}_{2}=$ hydrostatic pressure at section $2, \quad W=$ weight of water within the jump, $\phi=$ the bed slope and $F_{f}=$ friction force.

The friction force is assumed to be negligible, given that the jump length is short, the weight of water in the jump zone ignored the irregularities of the water surface, and the velocity distribution is uniform, then the Eq. (1) becomes:

$$
\frac{Q^{2}}{g A_{2}}+A_{2} \bar{d}_{2}=\frac{Q^{2}}{g A_{1}}+A_{1} \bar{d}_{1}+L_{j}\left(A_{a v}\right) \sin \phi
$$

Where $A_{1}=$ cross-section area at section $1, A_{2}=$ crosssection area at section $2, A_{a v}=$ mean area $\left(\left(A_{1}+A_{2}\right) / 2\right)=$ area centroid at section $1, L_{j}=$ length of the jump, $\bar{d}_{1}=$ distance of the centroid from the water surface at section 1 and $\bar{d}_{2}=$ distance of the centroid from the water surface at section 2. The two sides of Eq. (2) maybe divided by $D^{3}$, give the dimensionless specific force as:

$$
F_{1^{*}}=\frac{Q_{*}^{2}}{A_{1^{*}}}+A_{1^{*}} \bar{d}_{1^{*}}+L_{j}\left[A_{a v}\right] \sin \phi=F_{2^{*}}=\frac{Q_{*}^{2}}{A_{2^{*}}}+A_{2^{*}} \bar{d}_{2^{*}}
$$

Where $F_{1 *}=$ relative specific force at section $1, Q_{*}=$ the dimensionless flow discharge, $\left(Q_{*}=Q / \sqrt{g D^{5}}\right), A_{1} *$ the dimensionless cross-section area of the partially filled conduit at section $1\left(A_{1^{*}}=A_{1} / D^{2}\right)$ and $\bar{d}_{1^{*}}=$ the relative distance of the centroid from the water surface of the segment area at section $1\left(\bar{d}_{*}=\bar{d} / D\right), D=$ the internal diameter of the circular channel, $F_{2 *}=$ relative specific force at section $2, A_{2^{*}}=$ the dimensionless cross-section area of the partially filled conduit at section 2 and $\bar{d}_{2^{*}}=$ the relative distance of the centroid from the water surface of the segment area at section 2 .

The Froude number is an important dimensionless parameter defined as

$$
F_{r}^{2}=\frac{Q^{2} T}{g A^{3}}=\frac{Q_{*}^{2} T_{*}}{A_{*}^{3}} .
$$

where $F_{r}=$ Froude number, $T=$ top width, and $T_{*}=$ dimensionless top width.

\section{A. Geometric Properties of Circular Section}

The dimensionless cross-sectional area of the partially filled cross-section area of the channel may be written as follows:

$$
A_{*}=\frac{A}{D^{2}}=\frac{\theta-\sin \theta}{8} \text {. }
$$

where $\theta=$ central angle of segment area, Figure (2)

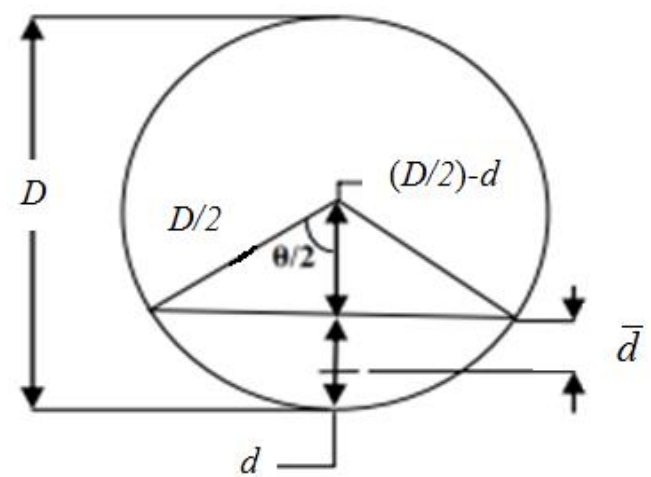

Figure (2) Definition Sketch of Partially Filled Circular Channel

It can estimate the value of the central angle of the crosssectional area of a partially filled circular channel as follows:

$$
\theta=2 \cos ^{-1}(1-2 d)
$$

where $d=$ the normal water depth $(d=y \cos \phi)$ and $y$ is vertical water depth, Figure (1).

From Figure (2) the top width may be written as follows; 
$T=2 \sqrt{D d-(d)^{2}}$

\section{II.2 DIMENSIONLESS HYDROSTATIC FORCE:}

The dimensionless relative centric depth of the segment area from the free surface of the water, maybe written as follows,

$$
\bar{d}_{*}=\frac{2}{3} \frac{\left[\left(d_{*}\right)-\left(d_{*}\right)^{2}\right]^{3 / 2}}{A_{*}}-\left[\frac{1}{2}-\left(d_{*}\right)\right]
$$

Where $d_{*}=$ the relative normal water depth $\left(d_{*}=d / D\right)$

From Eq. (5) and Eq. (8) the dimensionless hydrostatic force affecting the jump may be written as:

$$
A_{*} \bar{d}_{*}=\frac{2}{3}\left[\left(d_{*}\right)-\left(d_{*}\right)^{2}\right]^{3 / 2}-A_{*}\left[\frac{1}{2}-\left(d_{*}\right)\right] \ldots
$$

\section{Dimensionless specific force}

The dimensionless specific force can be calculated from Eq. (3). Eq. (3) may be rearrangement in terms of critical flow as follows.

For critical flow, $\left(F_{r 1}=1\right)$ and $\left(d=d_{c}\right)$ in Eq. (4):

$Q_{*}{ }^{2}=\frac{A_{c^{*}}{ }^{3}}{T_{c^{*}}}$

Where $\left(A_{c^{*}}\right)=$ the critical cross-sectional area of the partially filled circular channel $A_{c^{*}}=\left(A_{c} / D^{2}\right)$ and $T_{C} *$ is the critical top width of flow $\left[T_{c^{*}}=\left(T_{c} / D\right)\right]$.

Eq. (10) can be written as;

$$
Q_{*}^{2}=\frac{\left[2 \cos ^{-1}\left(1-2\left(d_{c^{*}}\right)\right)-\sin \theta_{c}\right]^{3}}{1024 \sqrt{\left(\left(d_{c^{*}}\right)-\left(d_{c^{*}}\right)^{2}\right)}} \text {. }
$$

Where $d_{c^{*}}=$ the relative critical water depth and $\theta$ is the critical central angle of the cross-sectional area of the partially filled circular channel.

Replacing Eq. (8) and Eq. (11) in Eq. (3) it can get the downstream dimensionless specific force as follows:

$$
\begin{aligned}
& F_{2^{*}}=\frac{\left[2 \cos ^{-1}\left(1-2\left(d_{c^{*}}\right)\right)-\sin \theta_{c}\right]^{3}}{128\left[\sqrt{\left(\left(d_{c^{*}}\right)-\left(d_{c^{*}}\right)^{2}\right)}\right]\left[2 \cos ^{-1}\left(1-2\left(d_{*}\right)\right)-\sin \theta\right]} \\
& +\frac{2}{3}\left(\left(d_{*}\right)-\left(d_{*}\right)^{2}\right)^{3 / 2} \\
& -\left[\left(2 \cos ^{-1}\left(1-2\left(d_{*}\right)\right)-\sin \theta\right) / 8\right]\left[0.5-\left(d_{*}\right)\right]+L_{j_{*}}\left(A_{a v^{*}}\right) \sin \phi
\end{aligned}
$$

\section{Energy dissipated by the jump}

The energy loss occurs during the hydraulic jump. This loss of energy in the jump is equal to the differences between upstream and downstream specific energies of the hydraulic jump. The dimensionless energy dissipated by the jump may be written as:

$$
\Delta E_{*}=d_{1^{*}}+\left(Q_{*}^{2} / 2 A_{1^{*}}^{2}\right)-d_{2^{*}}-\left(Q_{*}^{2} / 2 A_{2^{*}}^{2}\right) .
$$

Where $\Delta E_{*}=$ the relative head loss $\left(\Delta E_{*}=\Delta E / D\right), d_{1^{*}}=$ the relative upstream normal water depth and $d_{2^{*}}=$ the relative downstream normal water depth.

Also, the efficiency of the jump $(\eta)$ expressed as:

$$
\eta=\Delta E_{*} / E_{*_{1}}
$$

where $\eta=$ the efficiency of the hydraulic jump and $E_{1^{*}}=$ the relative upstream specific energy.

\section{EXPERIMENTAL WORK}

Tests were conducted in flume as shown in Figure (3). It was with a mild slope equal to 0.000883 by dropping the end of flume $0.5 \mathrm{~cm}$ down the inlet where the flume length is $6.0 \mathrm{~m}$ long. Water was pumped from an underground tank into a flume by 10 H.P pump. A series of runs at varied values of discharge experimented and the hydraulic jumps were formed by operating the tailgate and upstream gate. For each run initial depth, sequent depth and length of hydraulic jump were measured. The discharge in the channel is evaluated by using a sharp-crested rectangular steel notch.

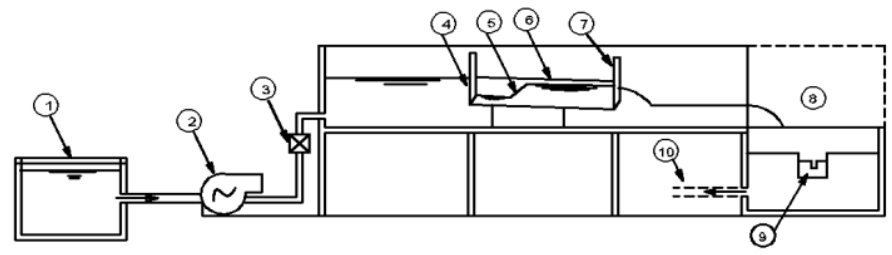

Figure (3) Schematic Diagram for flume

1-Constant water tank

3- Control valve

5- The hydraulic jump

7- Downstream sluice gate

9- Rectangular notch

The flume with circular cross-section $25 \mathrm{~cm}$ outer diameter and $24.2 \mathrm{~cm}$ inner diameter shown in Plate (1). Measurement of depths in the piezometers can be used for water surface computation in open channels. The variations of the flow free surface are predicted experimentally.

A laboratory 40 experimental runs in the circular flume with a mild slope for eight discharges ranged from 3.92 to 12.07 $1 / \mathrm{sec}$ was conducted. The recorded discharges are shown in Table (1).

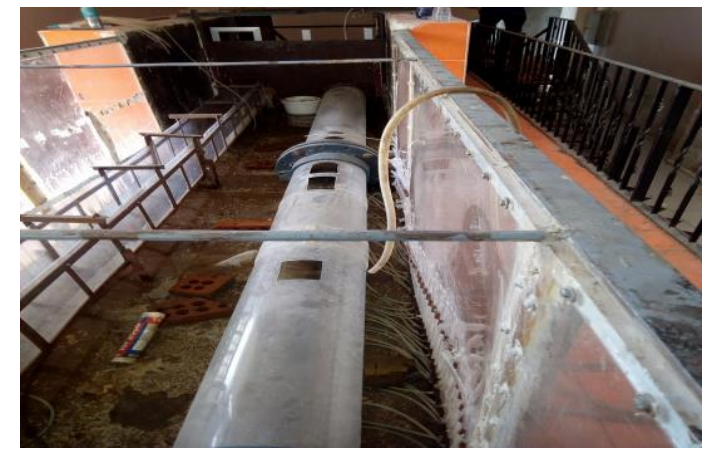

Plate (1) Experimental flume

\section{RESULTS AND DISCUSSION}

The given variables in the problem are the discharge, $Q$, the inner diameter of the circular channel, $D$, the length of the 
hydraulic jump, the bed slope and the sequent water depth $d_{2}$ , which known from the experimental work. The method of analytical solution is explained by the following steps:

TABLE (1)

EXPERIMENTAL MEASUREMENTS

\begin{tabular}{|c|c|c|c|c|c|}
\hline $\begin{array}{c}\text { Run } \\
\text { No }\end{array}$ & $\begin{array}{c}Q \\
\mathrm{~cm}^{3} / \mathrm{s}\end{array}$ & $\begin{array}{l}y_{2} \\
\mathrm{~cm}\end{array}$ & $\begin{array}{c}\text { Run } \\
\text { No }\end{array}$ & $\begin{array}{c}Q \\
\mathrm{~cm}^{3} / \mathrm{s}\end{array}$ & $\begin{array}{l}y_{2} \\
\mathrm{~cm}\end{array}$ \\
\hline 1 & \multirow{5}{*}{12067.5} & 12.1 & 21 & \multirow{5}{*}{7636.1} & 9.8 \\
\hline 2 & & 14.7 & 22 & & 10.5 \\
\hline 3 & & 16 & 23 & & 13.1 \\
\hline 4 & & 18.1 & 24 & & 15 \\
\hline 5 & & 19.6 & 25 & & 15.8 \\
\hline 6 & \multirow{5}{*}{11395.9} & 11.5 & 26 & \multirow{5}{*}{6253.5} & 9 \\
\hline 7 & & 13.4 & 27 & & 10.2 \\
\hline 8 & & 15.2 & 28 & & 11 \\
\hline 9 & & 16.2 & 29 & & 12.9 \\
\hline 10 & & 17.4 & 30 & & 14.9 \\
\hline 11 & \multirow{5}{*}{10339} & 10.9 & 31 & \multirow{5}{*}{5675.5} & 8.5 \\
\hline 12 & & 12.8 & 32 & & 9.9 \\
\hline 13 & & 14.2 & 33 & & 11.2 \\
\hline 14 & & 16 & 34 & & 12.8 \\
\hline 15 & & $\begin{array}{l}17.9 \\
\end{array}$ & 35 & & 13.5 \\
\hline 16 & \multirow{5}{*}{9793.9} & 10.9 & 36 & \multirow{5}{*}{3924.3} & 7.5 \\
\hline 17 & & 12 & 37 & & 8.8 \\
\hline 18 & & 13.2 & 38 & & 10.1 \\
\hline 19 & & 14.9 & 39 & & 10.9 \\
\hline 20 & & 15.7 & 40 & & 12.1 \\
\hline
\end{tabular}

1. The first step of the solution is to compute the relative sequent specific force $F_{2^{*}}$ from Eq. (3),

2. The first step of the solution is to compute the relative sequent specific force $F_{2^{*}}$ from Eq. (3),

3. By trial and error in Eq. (3) assume a value of relative initial water depth $d_{1}$, which gives the dimensionless specific force $F_{1^{*}}$ equals to $F_{2^{*}}$,

4. Compute the other flow characteristics of the hydraulic jump, such as initial Froude number $F_{r 1}$, sequent Froude number $F_{r 2}$, initial specific energy $E_{1}$, sequent specific energy $E_{2}$, energy loss $\Delta E_{*}$ and efficiency $\eta$ as presented in Table (2).

Relationships between various parameters affected the hydraulic jump was presented in graphs.

\section{IV.1 WATER SURFACES PROFILES}

The water surface profiles for different types of hydraulic jumps were painted in curves to observe the length of the jump and know the nature of the surface of the water during every jump. The water surface profile with a hydraulic jump on a mild slope with an upstream Froude number equal to 4.23 is shown in Figure (4). This curve of the water surface was given by the following equation: $y=-0.0007 x^{2}+0.2725 x-10.889 \ldots \ldots R^{2}=0.9970 \ldots .(15)$
Where $y=$ the vertical water depth and $x=$ the horizontal distance from the upstream gate.

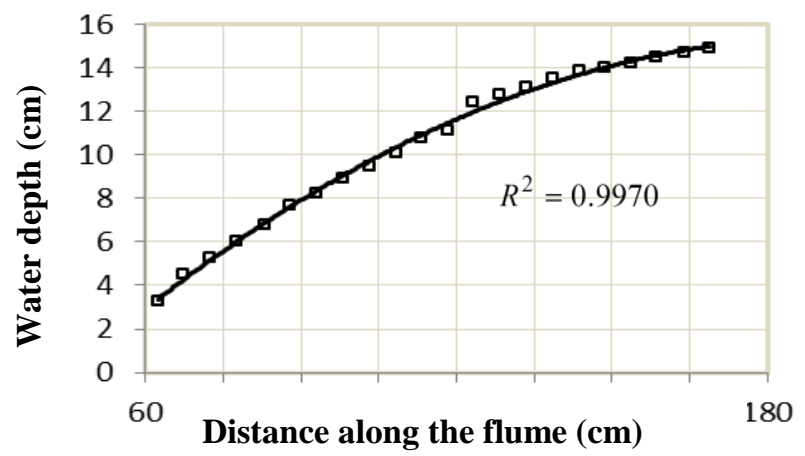

Figure (4) Water surface profile for jump, $\left(F_{r 1}=4.23\right)$

The variation of hydraulic jump characteristics like conjugated depth ratio, the relative height of the jump, and relative length of the jump, relative energy loss with approach Froude number and efficiency of the jump are shown below.

\section{IV.2 SEQUENT DEPTHS RELATIONSHIP}

The changes in the relative initial depth $d_{1^{*}}$, versus the relative sequent depth $d_{2} *$ of different relative critical depths $d_{c^{*}}$, are presented in Figure (5).

According to Figure (5), the relative sequent depth $d_{2} *$ increase with decreasing the relative initial depth $d_{1}$ *

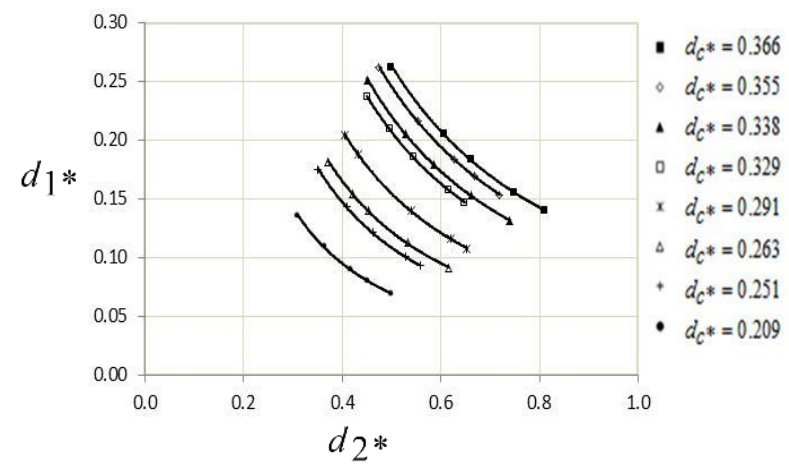

Figure (5) Relation between the relative initial depths, versus relative sequent depth for different values of critical water depth

IV.3 RELATIONSHIP BETWEEN THE UPSTREAM FROUDE NUMBER $F_{r 1}$ AND DOWNSTREAM FROUDE NUMBER $F_{r 2}$

The relationship between the Upstream Froude Number $F_{r 1}$ and Downstream Froude Number $F_{r 2}$ for varies values $d_{c^{*}}$ are presented in Figure (6). According to Figure (6), the downstream Froude Number $F_{r 2}$ increases with a decrease in the Upstream Froude Number $F_{r 1}$.

The relation between the upstream Froude number and the downstream Froude number of the hydraulic jump flow where the best-fitting curve give a function as follows:

$F_{r 1}=0.8163\left(F_{r 2}\right)^{-1.377}$ 
TABLE (2)

CHARACTERISTICS OF THE HYDRAULIC JUMP, SUCH AS INITIAL FROUDE NUMBER $F_{r 1}$, SEQUENT FROUDE NUMBER $F_{r 2}$, INITIAL SPECIFIC ENERGY $E_{1 *}$, SEQUENT SPECIFIC ENERGY $E_{2 *}$, ENERGY LOSS $\Delta E_{*}$, AND EFFICIENCY $\eta$.

\begin{tabular}{|c|c|c|c|c|c|c|c|c|c|c|c|c|}
\hline $\begin{array}{l}\text { Run } \\
\text { No. }\end{array}$ & $Q_{*}$ & $d_{c *}$ & $d_{1 *}$ & $F_{1 *}$ & $F_{r 1}$ & $E_{1 *}$ & $d_{2 *}$ & $F_{2 *}$ & $L_{j *}$ & $F_{r 2}$ & $E_{2 *}$ & $(\eta) \%$ \\
\hline 1 & \multirow{5}{*}{0.1337} & \multirow{5}{*}{0.366} & 0.26 & 0.129 & 1.90 & 0.938 & 0.50 & 0.130 & 4.61 & 0.55 & 0.618 & 34.1 \\
\hline 2 & & & 0.21 & 0.166 & 3.06 & 1.551 & 0.61 & 0.168 & 5.46 & 0.38 & 0.681 & 56.1 \\
\hline 3 & & & 0.18 & 0.192 & 3.81 & 2.041 & 0.66 & 0.193 & 5.04 & 0.32 & 0.721 & 64.7 \\
\hline 4 & & & 0.16 & 0.239 & 5.28 & 3.153 & 0.75 & 0.240 & 4.40 & 0.25 & 0.794 & 74.8 \\
\hline 5 & & & 0.14 & 0.278 & 6.54 & 4.254 & 0.81 & 0.278 & 3.95 & 0.21 & 0.849 & 80.0 \\
\hline 6 & \multirow{5}{*}{0.1263} & \multirow{5}{*}{0.355} & 0.26 & 0.117 & 1.81 & 0.872 & 0.48 & 0.118 & 3.99 & 0.57 & 0.596 & 31.7 \\
\hline 7 & & & 0.22 & 0.142 & 2.62 & 1.259 & 0.55 & 0.142 & 4.41 & 0.43 & 0.636 & 49.5 \\
\hline 8 & & & 0.18 & 0.172 & 3.61 & 1.847 & 0.63 & 0.173 & 3.78 & 0.34 & 0.689 & 62.7 \\
\hline 9 & & & 0.17 & 0.192 & 4.26 & 2.290 & 0.67 & 0.193 & 3.36 & 0.30 & 0.722 & 68.5 \\
\hline 10 & & & 0.15 & 0.219 & 5.15 & 2.965 & 0.72 & 0.220 & 3.36 & 0.26 & 0.764 & 74.2 \\
\hline 11 & \multirow{5}{*}{0.1146} & \multirow{5}{*}{0.338} & 0.25 & 0.103 & 1.78 & 0.816 & 0.45 & 0.105 & 5.47 & 0.58 & 0.565 & 30.7 \\
\hline 12 & & & 0.21 & 0.126 & 2.63 & 1.204 & 0.53 & 0.127 & 5.04 & 0.42 & 0.605 & 49.8 \\
\hline 13 & & & 0.18 & 0.149 & 3.45 & 1.661 & 0.59 & 0.149 & 4.86 & 0.35 & 0.646 & 61.1 \\
\hline 14 & & & 0.15 & 0.182 & 4.69 & 2.484 & 0.66 & 0.184 & 4.40 & 0.28 & 0.706 & 71.6 \\
\hline 15 & & & 0.13 & 0.227 & 6.40 & 3.812 & 0.74 & 0.227 & 3.57 & 0.22 & 0.775 & 79.7 \\
\hline 16 & \multirow{5}{*}{0.1085} & \multirow{5}{*}{0.329} & 0.24 & 0.100 & 1.90 & 0.840 & 0.45 & 0.101 & 4.40 & 0.55 & 0.554 & 34.1 \\
\hline 17 & & & 0.21 & 0.112 & 2.41 & 1.064 & 0.50 & 0.113 & 3.77 & 0.46 & 0.577 & 45.8 \\
\hline 18 & & & 0.19 & 0.128 & 3.03 & 1.381 & 0.55 & 0.130 & 5.04 & 0.38 & 0.609 & 55.9 \\
\hline 19 & & & 0.16 & 0.159 & 4.23 & 2.101 & 0.62 & 0.159 & 4.40 & 0.30 & 0.663 & 68.4 \\
\hline 20 & & & 0.15 & 0.174 & 4.83 & 2.513 & 0.65 & 0.175 & 4.40 & 0.27 & 0.691 & 72.5 \\
\hline 21 & \multirow{5}{*}{0.0846} & \multirow{5}{*}{0.291} & 0.20 & 0.075 & 1.99 & 0.773 & 0.40 & 0.076 & 4.61 & 0.53 & 0.490 & 36.6 \\
\hline 22 & & & 0.19 & 0.082 & 2.35 & 0.912 & 0.43 & 0.083 & 5.07 & 0.46 & 0.504 & 44.7 \\
\hline 23 & & & 0.14 & 0.116 & 4.18 & 1.824 & 0.54 & 0.118 & 4.81 & 0.30 & 0.581 & 68.1 \\
\hline 24 & & & 0.12 & 0.151 & 6.10 & 3.057 & 0.62 & 0.152 & 3.77 & 0.23 & 0.649 & 78.8 \\
\hline 25 & & & 0.11 & 0.167 & 7.01 & 3.721 & 0.65 & 0.169 & 3.57 & 0.21 & 0.678 & 81.8 \\
\hline 26 & \multirow{5}{*}{0.0693} & \multirow{5}{*}{0.263} & 0.18 & 0.060 & 2.07 & 0.722 & 0.37 & 0.060 & 4.20 & 0.51 & 0.444 & 38.5 \\
\hline 27 & & & 0.15 & 0.071 & 2.84 & 1.014 & 0.42 & 0.072 & 4.81 & 0.40 & 0.473 & 53.3 \\
\hline 28 & & & 0.14 & 0.081 & 3.46 & 1.292 & 0.45 & 0.081 & 3.98 & 0.35 & 0.497 & 61.5 \\
\hline 29 & & & 0.11 & 0.108 & 5.32 & 2.284 & 0.53 & 0.109 & 4.40 & 0.26 & 0.561 & 75.4 \\
\hline 30 & & & 0.09 & 0.144 & 8.02 & 4.086 & 0.62 & 0.146 & 3.99 & 0.20 & 0.636 & 84.4 \\
\hline 31 & \multirow{5}{*}{0.0629} & \multirow{5}{*}{0.251} & 0.18 & 0.052 & 2.02 & 0.670 & 0.35 & 0.053 & 5.04 & 0.52 & 0.421 & 37.2 \\
\hline 32 & & & 0.14 & 0.065 & 2.99 & 1.027 & 0.41 & 0.066 & 4.63 & 0.39 & 0.455 & 55.7 \\
\hline 33 & & & 0.12 & 0.081 & 4.15 & 1.554 & 0.46 & 0.081 & 3.99 & 0.31 & 0.496 & 68.1 \\
\hline 34 & & & 0.10 & 0.105 & 6.05 & 2.603 & 0.53 & 0.105 & 3.78 & 0.24 & 0.553 & 78.8 \\
\hline 35 & & & 0.09 & 0.117 & 7.04 & 3.230 & 0.56 & 0.117 & 4.20 & 0.21 & 0.579 & 82.1 \\
\hline 36 & \multirow{5}{*}{0.0435} & \multirow{5}{*}{0.209} & 0.14 & 0.036 & 2.33 & 0.642 & 0.31 & 0.036 & 6.59 & 0.46 & 0.358 & 44.3 \\
\hline 37 & & & 0.11 & 0.046 & 3.55 & 1.054 & 0.36 & 0.047 & 7.22 & 0.34 & 0.395 & 62.6 \\
\hline 38 & & & 0.09 & 0.060 & 5.23 & 1.765 & 0.42 & 0.061 & 6.39 & 0.26 & 0.439 & 75.1 \\
\hline 39 & & & 0.08 & 0.070 & 6.52 & 2.407 & 0.45 & 0.071 & 5.03 & 0.23 & 0.468 & 80.6 \\
\hline 40 & & & 0.07 & 0.088 & 8.87 & 3.746 & 0.50 & 0.089 & 4.62 & 0.18 & 0.513 & 86.3 \\
\hline
\end{tabular}






Figure (6) Relationship between upstream Froude numbers $F_{r 1}$ versus the downstream Froude number $F_{r 2}$

IV.3 RELATIONSHIP BETWEEN THE UPSTREAM DEPTH RATIO $d_{1} * d_{c} *$ AND UPSTREAM FROUDE NUMBER $F_{r} 1$

Figure (7) shows that the conjugated depth ratio $d_{1^{*}} / d_{c^{*}}$ increases with a decrease in the initial Froude number $F_{r 1}$. The obtained model gave an equation from Figure (7) as follows:

$\frac{d_{1 *}}{d_{c *}}=0.9942 F_{r 1}^{-0.507} \ldots \ldots \ldots \ldots \ldots \ldots R^{2}=0.9999$

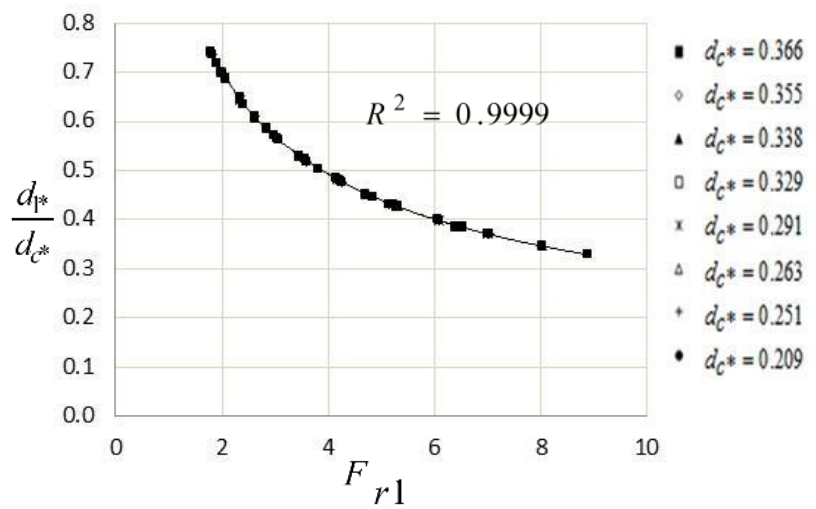

Figure (7) Relation between the ratios $d_{1} * / d_{c} *$ versus the initial Froude number $F_{r 1}$

IV.4 RELATIONSHIP BETWEEN THE CONJUGATED DEPTH RATIO $d_{2} * / d * 1$ AND UPSTREAM FROUDE NUMBER $F_{r 1}$

Figure (8) shows the relationship between the ratio of the conjugated depth $d_{2 *} / d * 1$ and the initial Froude number

$F_{r 1}$. In Figure (8), it can see that, there is a direct relationship between the conjugated depth ratio $d_{2} * / d * 1$ and Initial Froude Number $F_{r 1}$ was, by increasing the ratio of the conjugated depth $d_{2 *} / d * 1$, the value of the initial Froude number $F_{r 1}$ increases, an equation was given from Figure (8) as follows:

$$
d_{2^{*}} / d_{1^{*}}=1.0879\left(F_{r 1}\right)^{0.8824} \ldots \ldots \ldots \ldots R^{2}=0.9993
$$

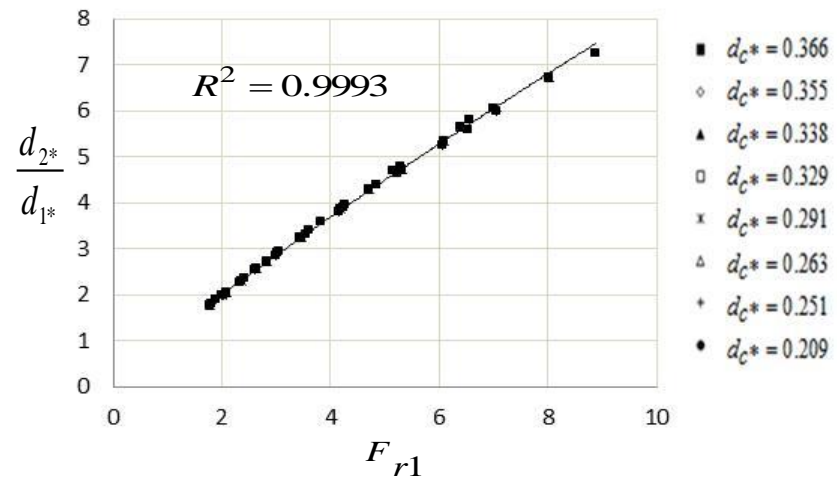

Figure (8) Relationship between the ratios of the conjugated depth $d_{2^{*}} / d_{* 1}$ versus the initial Froude number $F_{r 1}$

IV.5 RELATIONSHIP BETWEEN THE CONJUGATED DEPTH RATIO $d_{2^{*}} / d_{* 1}$ AND UPSTREAM FROUDE NUMBER $F_{r_{2}}$

From figure (9) New forms of equations were given to obtain the ratio of the sequent depth for the hydraulic jump with known discharge and sequent Froude number, In Figure (9) it can see that there is an inverse relationship between the ratio of the conjugated depth $d_{2^{*}} / d_{* 1}$, and sequent Froude number $F_{r 2}$ whereby increasing the ratio of the conjugated depth $d_{2 *} / d * 1$, the value of sequent Froude number $F_{r_{2}}$ decreases, an equation was given from the Figure (9) shown as:

$d_{2^{*}} / d_{1^{*}}=0.9081\left(F_{r 2}\right)^{-1.216} \ldots \ldots \ldots \ldots R^{2}=0.9994$

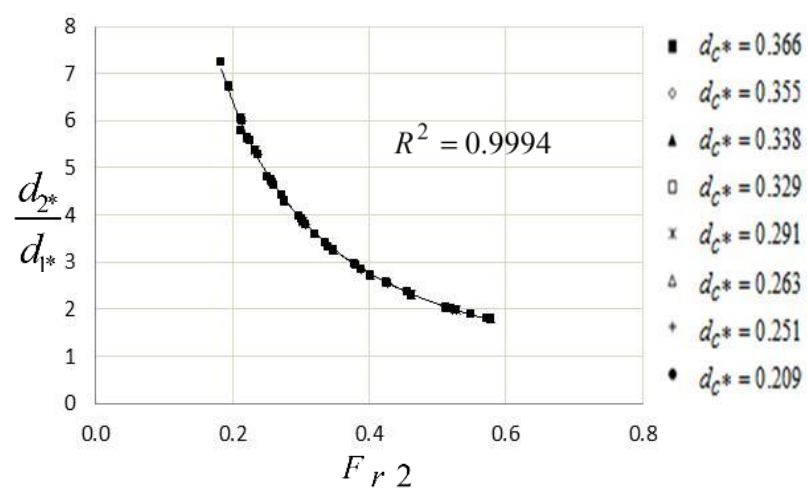

Figure (9) Relationship between the ratios of the conjugated depth $d_{2} * / d * 1$ versus sequent Froude number $F_{r 2}$

\section{IV.6 LENGTH OF THE HYDRAULIC JUMP:}

Figure (10) shows the relationship between the ratio $\left(L_{j} / d_{2^{*}}\right)$ and the downstream specific Force $F_{2} *$ In Figure (10) it can see that there is an inverse relationship between the length of the jump and the downstream specific force.

A developed equation was obtained from Figure (10) to relate the hydraulic jump length $\left(L_{j *} / d_{2 *}\right)$ with the downstream Froude number as follows:

$$
L_{j *} / d_{2 *}=1.9725\left(F_{2} *\right)^{-0.68} \ldots \ldots \ldots R^{2}=0.8273
$$




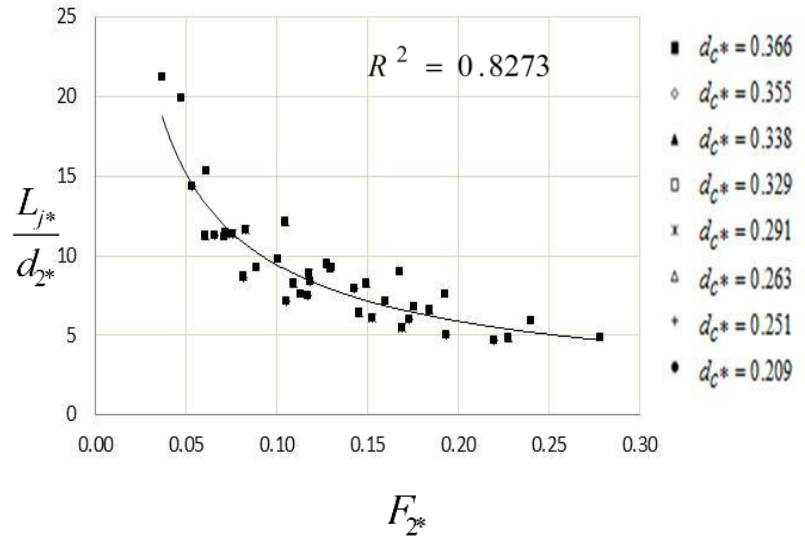

Figure (10) Relationship between the hydraulic jump length ratios $\left(L_{j *} / d_{2^{*}}\right)$ versus the Downstream Specific Force $F_{2^{*}}$

\section{IV.7 ENERGY DISSIPATED BY JUMP:}

Hydraulic jumps have been widely used for energy dissipation in hydraulic constructions. Many researchers have paid their attention to them for a long time.

Figure (11) shows the relationship between the conjugated depth ratio $d_{2^{*}} / d_{*_{1}}$ and the dimensionless specific energy dissipated by the jump $\Delta E_{*}$. In Figure (11) it can be seen that there is a direct relationship between the conjugated depth ratio $d_{2^{*}} / d_{*_{1}}$ and the specific energy dissipated by the jump $\Delta E_{*}$ were for same the value of conjugated depth ratio $d_{2^{*}} / d_{*_{1} 1}$, increasing the value of relative critical water depth led to increasing the specific energy dissipated by the jump $\Delta E_{*}$. Also from this Figure, it could be shown that by approaching the ratio of the conjugated depth $d_{2 *} / d * 1$ to unit value there is the minimum value of specific energy dissipated by the jump $\Delta E *$ for this discharge.

$$
d_{2^{*}} / d_{1^{*}}=3.5117\left(\Delta E_{*}\right)^{0.4685} \ldots \ldots \ldots \ldots R^{2}=0.9584 \ldots
$$

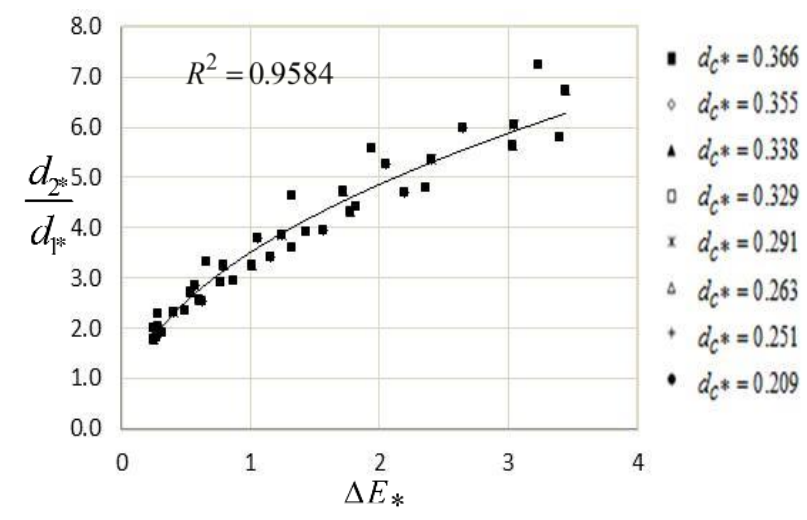

Figure (11) Relationship between the ratios of the conjugated depth $d_{2} * / d * 1$ versus the dimensionless specific energy dissipated by the jump

$\Delta E *$

Figure (12) shows the relationship between the initial Froude number $F_{r 1}$ and the dimensionless specific energy dissipated by the jump $\Delta E *$. In Figure (12) it can see that, there is a direct relation between the initial Froude number $F_{r 1}$ and the dimensionless specific energy dissipated by the jump $\Delta E *$, where for same the value of initial Froude number $F_{r 1}$, increasing the value of discharge and relative critical water depth $d_{c^{*}}$ led to increasing the dimensionless specific energy dissipated by the jump $\Delta E *$.



Figure (12) Relationship between the dimensionless specific energy dissipated by the jump $\Delta E_{*}$ versus the initial Froude number $\left(F_{r 1}\right)$

\section{IV.8 EFFICIENCY OF THE JUMP:}

The changes in the efficiency, versus the conjugated depth $d_{2 *} / d *_{1}$ of different relative critical depths, are illustrated in Figure (13). According to this Figure, the efficiency increase with increasing the ratio of the conjugated depth $d_{2} * / d * 1$. The relationship of the efficiency $\eta$ is introduced as a function of the ratio of the conjugated depth $d_{2 *} / d * 1$ of the hydraulic jump upstream as following:

$$
d_{2^{*}} / d_{1^{*}}=0.7941(e)^{0.024 \eta} \ldots \ldots \ldots \ldots . . R^{2}=0.9837
$$

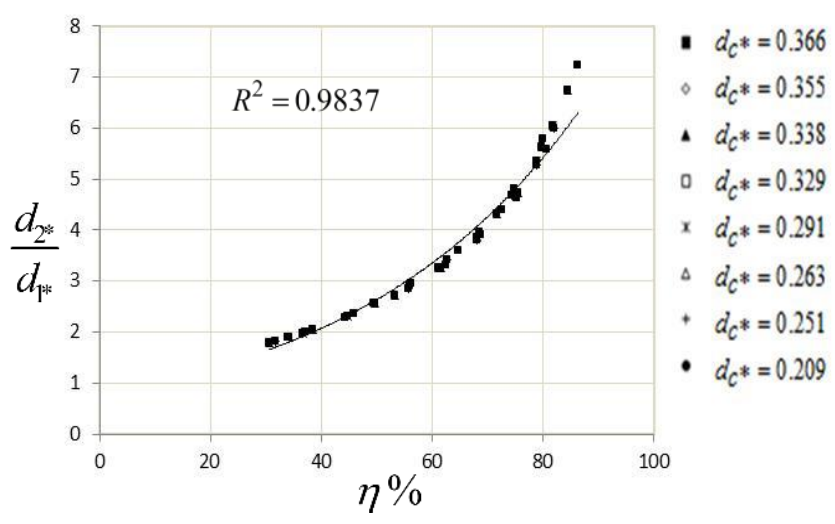

Figure (13) Relation between the ratios of the conjugated depth $d_{2} * / d * 1$, versus the efficiency $\boldsymbol{\eta}$ of different relative critical depths

\section{CONCLUSIONS}

A hydraulic jump is generally used to dissipate the high energy of flow to save structures such as spillways and save natural channel banks below hydraulic structures. This study discusses the characteristics of a hydraulic jump occurs in a circular channel with a mild slope. Following notes can be concluded from the study:

1. The analysis of experimental results led to obtaining a solution to the initial depths of the hydraulic jump 
in a circular section from known sequent depth for different values of critical depths,

2. An equation was developed to get the length of the jump from knowing the specific force for different values of relative critical depths,

3. Equations were presented the upstream Froude number, the downstream Froude number, the energy losses and the efficiency as functions in the relative conjugated depth,

4. Relative energy loss, efficiency, and initial Froude number increase when the conjugated depth ratios increases, and

5. An equation was presented to get the relationship between relative initial depths $d_{1 *} / d_{c^{*}}$ with the upstream Froude number.

\section{References}

[1] Azimi1 H, Shabanlou S, and Kardar S. " Characteristics of Hydraulic Jump in U-Shaped Channels. " Arabian Journal for Science and Engineering, 17 March (2017), p. 1-10.

[2] Bushra A, and Afzal N. "Hydraulic jump in circular and U-shaped Channels".journal of hydraulic research, (2006), Vol. 44, Issue 4, P. 567-576.

[3] Chow Ven Te. "Open channel hydraulics" McGraw-Hill, New York, (1959).

[4] Demetriou J and Dimitriou D. "Energy loss efficiency measured in hydraulic jumps within sloped channels". International Group for Hydraulic Efficiency Measurements, (2008).

[5] Ead S. A and Ghamry H. K. "hydraulic jumps in circular conduits". Annual Conference of the Canadian Society for Civil Engineering, (2002).

[6] Eyo A.E. "Hydraulic jump in a rectangular open channel with the abrupt channel in slope". Research Journal of Applied Sciences, (2011), Vol. 6, P. 31-37.

[7] Hager W.H. "B-jump in sloping channel" Journal of hydraulic research, (1989), Vol. 26, No.5, P. 539-558.

[8] Hager W.H.; Wanoschek R.: Hydraulic jump in the triangular channel. Journal of Hydraulic Research. (1987), Vol. 25, No. (5), P.549-564.

[9] Khan S. A. "An analytical Analysis of Hydraulic Jump in Triangular Channel: A Proposed Model". J. Inst. Eng. India Ser. A (2013), Vol. 94, No. 2, P 83-87.

[10] Mitchell S.B. "Hydraulic jumps in trapezoidal and circular channels". Proceeding of the ICE Water Management, (2008), Vol. 161, Issue 3, P. 161-167.

[11] Rashwan, I.M.H. "hydraulic jump in circular open channels". Mansoura Engineering Journal (MEJ), (2004) Vol. 29, No. 2.

[12] Rashwan, I.M.H."A-jump in horizontal inverted semicircular open channels".Ain Shams Engineering Journal, 2013, Vol.4, P. 585-592.

[13] Rajaratnam N. and Murahari V. "flow characteristics of sloping channel jumps ".Journal of the Hydraulics Division, (1974), Vol. 100, No.HY6, p. 731-740.

[14]Reham A. I., "hydraulic jump in the horizontal circular open channel ". 2015.

[15] Stahl H and Hager W.H. "Hydraulic jump in circular pipes". Canadian Journal of Civil Engineering, (1999), Vol. 26, Issue 3, P. 368-373.

[16] Vatankhah A.R and Omid M.H. "Direct solution to problems of a hydraulic jump in horizontal triangular channels". Applied Mathematics Letters, Vol. 23, (2010), P. 1104-1108.

[17] Wang C, and Samuel Li S." Hydraulic Jump and Resultant Flow Choking in a Circular Sewer Pipe of Steep Slope"Water 2018, Vol. 10, No. 1674. 